\title{
Creating Structure out of Chaos in a Virtual Learning Environment to Meet the Needs of Today's Adult Learner
}

\author{
Bob Barrett, Member, IEDRC
}

\begin{abstract}
Due to economic reasons and personal needs, many adults have decided to return back to institutions of higher learning for additional education and training. While these adult learners have been seeking additional education and training either for professional advancement, career development or personal growth, some have found that one degree is perhaps not enough for them to excel both personally and professionally. As a result, we are seeing more adult learners starting to examine this type of long-term investment in terms of whether or not this additional education and training will help them during their lifelong learning endeavors. Adult learners want to be able to apply whatever knowledge and skill they gain today to life more effective tomorrow." Thus, this does raise the question of whether or not our educational institutions are offering enough learning opportunities to help satisfy the needs of today's adult learner, as well as meeting the growing workforce needs of society's business needs. This paper will help to examine the learning style, learning activities, and social interaction that adult learners face in today's educational institutions in terms of whether they prefer teacher-centered versus student-centered approaches to learning.
\end{abstract}

Index Terms-Student-centered learning, teacher centered learning, adult learning, online learning.

\section{INTRODUCTION TO ADULT LEARNERS AND ONLINE LEARNING}

While economic times have changed, the typical adult learner and his or her learning needs have also changed. In the past several years, more and more adults have had to take upon one or more jobs in order to survive. However, they have also found it a bit impossible or self-defeating to work several jobs and rush to a college campus to take courses in order to better oneself and/or obtain a degree in order to advance in their field or another field of career choice.

The key factor that is facing many adults in today's workplace is the technological changes that have affected not only the use of machinery, but how one interacts, performs, and is evaluated overall as an employee. Harris (2000) noted that the "new workplace requires a new type of employee, one who is highly skilled, flexible, creative, and attuned to working as a member of a team" (p. 1). [1] As a result of this change in the workplace, even today's instructors have to make changes and adjustments in not only their teaching skills sets, but also in how they interact and perform as an instructor and employee. Therefore, in order to prepare our instructors for this type of new employee, academic

Manuscript received November 12, 2012; revised January 19, 2013.

Bob Barrett is with the School of Business at American Public University, Charles Town, WV 25414 USA (e-mail: docjob00@msn.com). institutions need to utilize different types of recruiting and hiring methods to find the best-qualified instructors for today's online learning environment. Further, there is a greater need to focus on training online instructors to be able to work with the training entities, whether it is an institution of higher education or training learning center, in order to develop, design, implement, and evaluate current and future educational and/or training offerings. Thus, it is important to realize that both education and training for the workplace has changed drastically, and academia will have to make concessions and implement changes. These needs and changes are starting to be recognized both by federal and state agencies.

In 2013, the U. S. Department of Education viewed these changes in terms of skills sets and literacy. They wrote that "Workplace education programs focus on the literacy and basic skills training workers need to gain new employment, retain present jobs, advance in their career, or increase productivity. Curricula are developed by educators, working with employers and employee groups, who assemble written materials used on the job and who analyze specific jobs to determine what reading, computation, speaking and reasoning skills are required to perform job tasks effectively. By their nature, successful efforts to institute workplace literacy programs require strong partnerships among educators, employers, and employees." [2] Thus, the need for changes in skills sets and various other skills of today's employees and adult learners started to emerge not only in the workplace, as well as the literature. Both trainers and academicians have seen changes in technology as the common linchpin to help facilitate the coming together of both the old way of doing things in the workplace, as well as coupling with the new computerized approaches being introduced across the business world. However, this type of transition has not been an easy pilgrimage for many trainers and educators - but their journey continues on a daily basis in order to meet the training and education needs - as well as meeting today's organizational and industry needs.

While more technology has become available in many parts of the world, a newer type of adult learner population has emerged with more learning requirements and needs. The traditional student image of higher learning has been somewhat impacted in some countries, but given the impact of the Internet, this traditional "student body" has been approaching their educational needs by seeking additional education within the world of virtual learning. During this change, or rather transition, from the traditional face-to-face (F2F) learning environment to a more technological and updated virtual learning environment, they have become more involved in learning with the use of technology and 
identify with other online learners with various learning communities. Preece (2000) wrote that these online communities "consists of people who interact socially as they strive to satisfy their own needs or perform special roles; a shared purpose that provides a reason for the community; policies that guide people's interactions; and computer systems to support and mediate social interaction and facilitate a sense of togetherness" (p. 10). [3] In the fields of business and management, instructors and administrators have recognized the changing demographics of this student population. If one looks at the virtual environment, the student is not the traditional student seen in a classroom in previous years, but rather one that reflects a vast array of cultural differences and needs that require educators to help build "new learning paths" towards the creation of virtual learning communities. Therefore, the online learning environment has offered a viable alternative for many working adults in their pursuit of additional education or career development opportunities.

As noted in the section above, adult learners, due to various economic, family, and personal reasons, they have been looking at alternatives to their educational and career pursuits in the area of distance education or online learning. Neal and Miller defined distance education as "education that takes place independent of location, in contrast to education delivered solely in the classroom, and that may be independent of time as well. [4] In addition, ASTD, an education/training \& development professional organization, noted that "distance education can be characterized as an educational situation in which the instructor and students are separated by time, location, or both. Education or training courses can be delivered to remote locations via synchronous or asynchronous means of instruction. [5] Therefore, we can see that more non-traditional students are taking advantage of online course offerings/programs. It should be noted also here that online learning may not be a viable solution for all adult learners, but it appears that more adult learners are now considering and acting upon the possibility.

As online learning continues to grow, technology has also changed to meet the many needs of both academia and business. These difference forms of technology have allowed educational institutions, educators, and instructors to provide education on a much higher playing field - in a virtual online learning environment. Thus, the business world has also worked with technology in this venture to help assist educational institutions in becoming more modern and adaptive for change. However, we have to wonder whether or not if these changes have signified to the educational and learning communities that technology recognizes a need for change or do we, as educators, recognize the need for change completely? Finally, we need to understand why many educational institutions, as well as the corporate world, are focusing on the learning process and its impact on their organizational structure and employees.

Consequently, we need to realize that the bottom line is that many adults are considering online learning to be a new academic outlet or option. Thus, one must also consider the next step for college graduates - the world of work. In general, the corporate business environment does differ from the academic setting, and more employees from both settings will always need some additional education or training. Even though online learning has been concentrated more on the academic setting, many organizations are learning that online learning has a varied of benefits to offer. Thus, many companies and organizations are focusing on the "learning" element of their employees' daily assignments and tasks, as well as helping to build their knowledge management with a concentration on helping the organization learn from previous and current experiences. As a result, many educational institutions are starting to examine their business curricula. However, in order to understand all of the changes that might need to be made to any schools' curriculum might be improved with an understanding of adult learning in general, as well as understand the needs of today's adult learner.

\section{Adult LEARNing THEORIES AND STRATEGIES}

We need to realize that not all adults learn in the same way. Also, instructors need to make some adjustments in their teaching style in order to meet both accreditation and student learning problems and expectations. Brookfield (2005) commented on critical theory's relevance for adult learning. Two important questions that we, as educators in the context of providing online instruction, must consider are:

- How do adults learn to interpret their experiences in ways that emphasize their connectedness to others and lead them to see the need for solidarity and collective organizations?

- How do adults learn to think critically by recognizing when an embrace of alternative views is actually supporting the status quo it appears to be challenging? [6]

Rather than just relying on previous learning experiences, all adult learners should view education as another challenge in their lifetime to work towards another goal and prove that learning is a necessity and a way to improve oneself. Mezirow (2000) noted that: "Transformative learning refers to the process by which we transform our taken-for-granted frames of references (meaning perspectives, habits of mind, mind-sets) to make them more inclusive, discriminating open, emotionally capable of change, and reflective so that they may general beliefs and opinions that will prove more true or justified to guide action." [7] Therefore, as student populations continue to change in the online learning environment, there will be a growing need for adaptation and modification of current frames of references to be done. Finally, Mezirow (2000) stated: “Transformation Theory's focus is on how we learning to negotiate and act on our own purposes, values, feelings, and meanings rather than those we have uncritically assimilated from others. - to gain greater control over our lives as socially responsible, clear-thinking decision makers." [7] Each of us need to realize that as technology transforms our learning environment, perhaps we, too, need to transform various components of our teaching and learning styles. Thus, we need to realize that there are also barriers in the online learning environment that need to be addressed. 
While many educational institutions realize that online learning offers fewer barriers for many students, there are certain barriers that still exist and need to be addressed. Drummond-Hay and Saidel (2004) commented on several barriers to knowledge sharing that could be applicable to the online learning environment.

- There is no recognition or reward for sharing knowledge.

- People are competitive and believe that their knowledge increases their power.

- There is no vehicle for storing and categorizing knowledge, or the existing vehicle is difficult to use.

- They don't know anyone would be interested in what they know.

- They don't share knowledge because they are not aware of what they know.[8]

If we consider the various barriers noted above, the author does note and strongly recommends a change of the status quo in order for the educational profession to move forward. Even though there are some educators who may still cling to the Socratic method of teaching, methods do and need to be changed and evaluated on a regular basis. We can learn from Socrates' example - that teaching does not have to occur inside a physical classroom - rather learning can occur in an open space (perhaps virtual?). Finally, rather than being focused on one form or style of teaching and learning, we, as educators, need to focus on our audience. Has the demographics of our student population changed over the past decade? If so, are we meeting the needs of our virtual learning communities - or just meeting the needs based on past teaching experiences? Thus, this leads us to our next area of discussion on the topic of teacher-centered versus learner-centered approaches used in various educational institutions and learning environment.

\section{TEACHER-CENTERED VERSUS LEARNER-CENTERED APPROACHES}

Traditionally, most educational institutions and instructors used the teacher-centered approach to education. Most students were indoctrinated with this approach, but due to fashionable changes and published students, there was a change in the educational approach towards a more learner-centered approach. Weimer (2002) noted that "in student learning is the focus of the class. On the other hand, in teacher-centered approaches, teaching practices are the focus of the session. [9] From another perspective, Hara (2009) that the "use of these strategies (positively or negatively) can affect student learning, teaching evaluations, or even tenure and promotion decisions. [10] Now let us look at some historical and legislative factors that have helped to support the learner-centered approach.

If we look at the passage of key education legislation, such as the No Child Left Behind, ADA, etc., there has been a growing need for documentation/evidence of academic achievement. This movement has been transforming today's classrooms from a teacher-centered approach to one of a learner-centered approach - the instructors are instructed to facilitate and guide the student through the various learning activities in order to help them achieve the learning objectives, as well as understand how they can contribute to the learning process. For example, one learning activities that some instructors have used is the e-portfolio process. With this learning activity, it is the student that ultimately selects their best work and begins his or her journal to develop his or her own e-portfolio. Therefore, e-portfolio serves not only in the academic achievement process, but they can be used as interview portfolios for students to share with potential employers.

\section{APPliCATIONS FOR USE IN LEARNER-CENTERED APPROACHES TO EDUCATION}

We can see in the literature and academic conferences that more educational institutions have started to use portfolios. In essence, we are seeing a new generation of portfolio approaches, but even more in a technological sense in terms of being more technically presented and displayed. Electronic Portfolios (e-Portfolios) have been defined in many different ways in terms of how they are designed and developed, as well as implemented and evaluated. According to the University of Berkeley: "An e-Portfolio functions like a file cabinet with file drawers and file folders. Students store personal, educational, career, skill assessment, non-academic/work experience, certification, and rewards information in their portfolios. The information placed in an ePorfolio is referred to as an artifact." [11]

Even though only a small percentage of educational institutions are quick to embrace and use extensive and developed e-Portfolio software systems, other educational organizations may want to contemplate their own creation and implementation of an e-Portfolio system (evaluative project). Goldsby and Fazal noted that student-created portfolios are commonly "used in teacher preparation programs to demonstrate teaching skills and expertise. This practice was introduced as test scores alone lack the comprehensive scope needed for effective assessment and evaluation, portfolios can be implemented to interpret/make decisions regarding learning of teaching competences"[12] In addition, eportconsortium, noted that the role and function of an E-Portfolio was: “. ... . [to] facilitate[e] and captur[e] the evolution of concepts and ideas through revisions of work and interactions with instructors, mentors, classmates and friends, electronic portfolios can be much more than a Web site that simply organizes and presents final projects. They can foster learning spaces where the author can gain insights and a better understanding of him/herself as a learner." [13]

With this considered, educational institutions can expect that there may be many different factor and needs to be considered here in terms of determine how an e-Portfolio system/project can be created, implemented, and eventually evaluated. Nonetheless, it is ultimate role of the educational institution to determine if there is a need and how it can be met in terms of an e-Portfolio approach. While the e-Portfolio approach may be more individualized in scope, there may be other learning applications used in the virtual learning environment. As a result, there may be a greater 
need for students to network and share their own learning and work experiences in order to benefit others, but also to learn from the experiences of others in their learning environment -specifically in particular sets of courses and/or their program of study.

\section{COMMUNity OF PRACTICES IN VIRTUAL LEARNING ENVIRONMENTS}

For the purpose of this paper, a "community of practice" can be defined as "groups of people who share similar goals and interests. In pursuit of these goals and interest, they employ common practices, work with the same tools, and express themselves in common language. Though such common activity, they come to hold similar benefits and value systems." [14] Lave and Wenger (1991) noted that situated learning is a type of learning can take place in the workplace or the classroom. One way to view this is in the lens of an apprentice learning on the job in terms of skills and experiences for use later in his or her profession. As one continues to work in a given work environment, skills and experiences are learned or shared, as well as contributions are made to the collective whole. Even though some of contributions may not be on the same level at more experienced, skilled, or educated professionals, this type of experience does demonstrate the beginnings of one's contribution and participation in the workplace in terms of knowledge management in one sense or another. Consequently, we can see participation in the workplace, academia or even in a virtual gather (learning situation) as a form of Legitimate Peripheral Participation (LPP), [15]. In this type of participation, we can view it as a social process in these described environments, whereas people join together for a common goal(s) and proceed to build upon each other's participation, contributions, and experiences. Consequently, they start to identify and buy into their "own" community of practice starting to be built by them, which tell not only a story about them and their interactions - but also how they create, value, and share their knowledge gained. While most of the literature has been focused on the learning community for students and community of practices for instructors, this paper will also look at what students can bring together as part of their own "community of practice as they struggle to identify with others within their virtual learning environment. Along this same line of thinking, let us now look at the different aspects of what Lave and Wenger (1991) called Legitimate Peripheral Participation (LPP) [16].

Legitimate Peripheral Participation (LPP) can be viewed in three aspects. According to Lave and Wenger (1991), LPP is composed of legitimation, peripherality, and participation separately. "Legitimation refers to the power and the authority relations in the community. Peripherality refers to the individual's social, rather than physical peripherlity in relation to the community. This in turn is dependent on their history of participation in the group and the expectation of their future participation in and interaction with the community." [15] As one looks at this participation in the given environment, one needs to look at the given action, product or experience as a whole. What is shared, distributed, or learned tells one about the community of practice and its relevance as a whole. In order to do this we look at what is common or the basis called by Clark and Brennan (1991) as the common ground. [16] With this concept in mind, we look at the environment, how information is shared or distributed, and the dynamics of the group in general. Thus, we need to understand the role and function of these communities of practices and how relevant they are to organizations and their employees. It should be noted at this juncture that these types of communities of practices are important as the various online adult learners work towards developing online relationships and participate in potential online group projects. While the concept of virtual learning is usually a relatively new concept for many adult learners, they can gain better and stronger online learning experiences with the assistance of veteran online learners and learning from their given classmates as a collective whole. While many traditional learners may view more chaos in the process of learner in terms of the logistics, attendance of class meetings, as well as balance their work and family lives in relationship to academic endeavors, we need to examine the value of their networking abilities. It should be noted that not all networking efforts and experiences will be the same, or of the same value, to all members of an online learning environment, there is perhaps a better chance of more social networking to occur and perhaps more opportunities to enhance the adult learner's overall online learning experience.

Why do some group members contribute more than others at various points of interactions with others or during different segments of a project or class assignment in the virtual learning environment? While the contributions of the group, as well as individuals, are quite important to the sharing, distribution, and maintaining of knowledge of the organization or environment in general, there is also a form of interaction with others outside of the given environment. It should be noted that learning many not always occur within the specific online learning course, but as a result of research, social networking, and general daily interactions with one's immediate circle of friends, co-workers, and family members. However, as members of a group, or community of practice, interact within their community, they are also part of networks out of their community. Otherwise, without this external interaction, the learning or knowledge gained within their communication of practice may be stagnant or being formed within a vacuum. Brown and Duguid (2000) looked at the value of these external networks and named them as Network of Practice (NoP). [17] What we can see as potential NoP are specialized groups or perhaps specific technological networks, suppliers or organizations from which certain communities of practices can gain or share valuable information in which to improve upon their own community and perhaps set up "particular networks" of value to them and their organization as a whole. These NoP can be important not only in the context of online learning, but as an experience for adult learners to apply to their professional lives and future career endeavors. Why do these networks prove to be a necessity? For many adult learners, they need to make sense out of their chaotic lives and to identify, or link up, with others who might share in the same experiences and need to do more with their lives in terms of more education and potential career development opportunities. 
Thus, we need to ask: Who are members of NoP? According to the works of Markus (2001), we can examined the work of these "shared work practitioners" as seeking others like them in characteristics, interests, and work goals. Markus (2001) viewed these shared work practitioners as doing similar work, but in different work settings. They are all seeking new knowledge and ways of performing their work goals, but yet learn other ways of enhancing their own community. They actively seek others in similar industries or organizations to interact or network with in meeting their own goals and perhaps learning more about new forms of technology and best practices. [18] Consequently, they help not only themselves, groups, and other organizations, but they also contribute to sometimes more than one NoP or CoP and increase value for all. Thus, we need to look a bit closer at who are the contributors to these communities of practice and how their contributions can add to the intellectual capital of their organizations and other related parties.

\section{Adult LEARNERS AS CONTRIBUTORS TO COMMUNITIES OF PRACTICE}

While many people can interact with various communities of practices, we need to look closely as who is contributing to these practice areas. Who are these contributors to the community of practice? If we look at the academic approach to communities of practice, there seem to be a growing eagerness to form such communities of various reasons. For adult learners, there is a need to make sense out of this new learning environment and to see how virtual learning and virtual interaction can benefit them and others. Yes, we need to keep in mind that learning itself can occur with the individual, but humans are social creatures. As a result, there is a greater need for some adult learners, as opposed to others, to link up with other similar learners to help each other during this transition to a new learning experience and environment overall. One key reason for academic groups to form such communities may be pair up new faculty members with seasoned faculty to help learn from them and perhaps build their own "form of expertise" within their group. Spased, Bessant, Partington, Tranfield, and Young (2002) noted that "academic communities typify the dynamics of collectively sharing identity, know-how, and ways of working independently of local contact."[19] Other than just sharing their own experiences and focus on new technology, these adult learners may see these communities of practice as another form of networking in terms of academic help, as well as potential career development opportunities.

While shared knowledge is beneficial to individuals, groups, and the organization as a whole, today's adult learners need to consider the importance of this networking and interaction, as well as how the various members are rewarded and given recognition for their efforts within these communities. Davidson and Voss (2002) stated that "a knowledge management initiative will not get very far if however actively you champion knowledge sharing - the existing remuneration system rewards knowledge hoarding." [20] Thus, while educational institutions are focusing on helping adults in terms of teambuilding within their organizations, they are also helping adult learners to learn and grow from each other's experiences.
While many academic organizations are creating and implementing their own communities of practice within their various academic divisions and schools, some educational institutions have seen positive effects and experiences shared among members of these communities. In fact, some of these communities are interacting within their various schools and its members, as well as crossing over to other schools and external communities to seek and share knowledge to advance and improve upon their own best practices. For example, the American Public University System (APUS) in the United States, has taken the initiative of creating separate communities of practices within their various schools in both of its universities - American Public University (APA) and American Military University (AMU). In addition to specific schools within their own university system, they have created common areas (based on the concept of common ground) for particular interest areas, whereas faculty and staff members in both universities can meet and exchange ideas and experiences. Some of these communities of practices consist of legal studies, career ideas, sports management, criminal justice, hospitality management, etc. (www.apus.edu). As a result, various members of these communities meet and exchange ideas within certain designated areas, as well as share with the community at large of their findings and plans for future activities. This only demonstrates a more concentrated effort to bring together the various academic work experiences of various members of different communities in the pursuit of enhancing the overall learning experience of academicians, administrators, and administrative staff. Further, this works as a strong foundation in which members of a learning community can work together to build greater work and learning experiences for all members of the overall organization and learning community.

\section{REALITY WITH RETURNING ADULT LEARNERS}

We need to consider what adult learners know and feel comfortable with in order to understand their learning needs and how to help them to become successful. For many new adult learners, they equate learning to what they know - how they were taught and supervised in their previous educational endeavors. For some new learners, they may have only experienced the teacher-centered approach. As a result, the movement towards entering the world of academia once more may be quite stressful and traumatic for some. While many educators advocate a learner-centered approach, especially with online studies, this may not work successfully in all cases. Just like best practices, even they are not fully applicable in all cases. In fact, some schools are rethinking their approach. In fact, some educational institutions may not support certain learning activities and/or approaches, but rather they may want to base their teaching and grading on how they were educated. Even though many of today's online instructors were educated with the teacher-centered approach, even they may be slow in implemented the best practice of learner-centered approach. After considering both the needs of current and previous adult learners, all instructors need to step back and examine whether or not if they could learn better with either one of these approaches or not. 


\section{CONCLUSIONS}

While returning back to school can be a daunting task for many adult students. For some they focus on how they were taught years ago and expect the same approach. However, for some the former teacher-centered approach has been one of the key reasons why they left their dream for a better education and career aspirations. In fact, some believe that if more educational institutions would adopt and implement the learner-centered approach, their enrollment numbers may increase. On the other hand, many online schools are offering the learner-centered approach in order to change the "status quo" of education and make more education try this system and forget about the old system. However, many current instructors are realizing that many of their adult learners realize and expect the old way of teaching to be used; namely, they expect the teacher-centered approach. Why? Well, they can relate better to this formal method of teaching, because they were exposed only to this approach over the years. Also, sometimes after a long day of working and thinking of other time commitments, they do not want to expand any more thought and time to the course focus on learned-centered approaches.

Even with an alternative to education, such as virtual learning, there is just as much likelihood of having chaos, misunderstandings, and repeat of earlier educational experiences. However, it is equally possible that there could be a reduction in these situational and impacting factors if the virtual learning experience is well planned and organized. This is why it is important for educational institutions to focus not only on the learner's experience in the virtual learning environment, but also evaluating and improving upon the instructor's input and teaching skills as well.

In any event, this is an individual educational institutional decision that many schools have started to realize that needs a plan of action and a team to oversee its activities. Nonetheless, the key aim of this paper has been to note that not all adult learners may or may not be willing to embrace the new learner-centered approach, but rather they may only want the option of the teacher-centered approach. The key dilemma is for a school to select one method of approaching learning for its students and to evaluate later on its' effectiveness.

\section{ACKNOWLEDGMENT}

Dr. Bob Barrett thanks Margaret Barrett Hendrickson for her contributions and input given during the creation of this article. Her insights have helped to offer a more balanced perspective of the views of today's adult learner and the process of returning back to higher education.

\section{REFERENCES}

[1] H. Harris, "Defining the future or reliving the past? Unions, employers, and the challenge of workplace learning," Columbus, $\mathrm{OH}$ ERIC Clearinghouse on Adult, Career, and Vocational Education, Information Series, no. 380, 2000.

[2] U.S. Department of Education, Fact Sheet 16, Washington, DC: Division of Adult Education and Literacy, Office of Vocational and Adult Education, USDE, March 2000.

[3] J. Preece. (2000). Online communities: Designing usability, supporting sociability. Chichester: Wiley.

[4] L. Neal and D. Miller. (2006). The basics of e-learning: An excerpt from Handbook of Human Factors in Web Design, para. 4-5. In R.W Proctor \& K.L. Vu (2004), Handbook of Human Factors in Web Design, Lawrence Erlbaum Associates. Retrieved March 19, 2008.
[Online].

Available: http://www.elearnmag.org/subpage.cfm?section=tutorials\&article=201.

[5] L. Neal and D. Miller. (2006). The basics of e-learning: An excerpt from Handbook of Human Factors in Web Design, para. 4-5. In R.W. Proctor \& K.L. Vu (2004), Handbook of Human Factors in Web Design, Lawrence Erlbaum Associates. Retrieved March 19, 2008. [Online]. Available: http://www.elearnmag.org/subpage.cfm?section=tutorials \&article=201.

[6] S. D. Brookfield. (2005). The power of critical theory: Liberating adult learning and teaching. San Francisco: Jossey-Bass, pp. 31.

[7] J. Mezirow, Learning as transformation, San Francisco: Jossey-Bass, 2000.

[8] P. Drummond-Hay and B. G. Saidel, "Capturing ideas, creating information, and liberating knowledge," in M. Goldsmith, H. Morgan, and A. J. Ogg, San Francisco: Jossey-Bass., 2004, pp. 293-295.

[9] M. Weimer. (2002). Learner-Centered Teaching: Five Key Changes to Practice. Jossey-Bass, San Francisco. [Online]. Available: http://www.amazon.com/Learner-Centered-Teaching-Five-Changes-P ractice/dp/0787956465/ref=sr_1_1 ?ie=UTF8\&s=books\&qid=125329 $6206 \& s r=8-1$.

[10] B. Hara. (2009). Teacher-Centered vs. Student-Centered Pedagogy. [Online].

Available: http://chronicle.com/blogs/profhacker/teacher-centered-vs-student-cen tered-pedagogy/22714

[11] LDP e-Portfolio Report. [Online]. Available: http://bearlink.berkeley.edu/ePortfolio/page5.html (retrieved 6/1/2008).

[12] G. Fazal, in John DiMarco, Web Portfolio Design and Applications, Idea Group Inc., pp. 607-608, 2006.

[13] Electronic Portfolio White Paper. http://eportconsortium.org.

[14] Collaborative Visualization Project (n.d.). Communities of practice. [Online]. http://www.covis.nwu.edu/info/philosophy/communities -of-practice.html.

[15] J. Lave and E. Wenger, Situated learning, Legitimate peripheral participation, Cambridge: University of Cambridge Press, 1991, pp. $39-40$.

[16] H. Clark and S. E. Brennan, "Grounding in communication," in L. B. Resnick, J. M. Levine, and S. D. Teasley (eds.), Perspectives on socially shared cognition, Washington, DC: American Psychological Association. 1991, pp. 127-149.

[17] J. S. Brown and P. Duguid, The social life of information, Boston, MA: Harvard Business School Press, 2000.

[18] M. L. Markus, "Towards a theory of knowledge reuse: Types of knowledge reuse situations and factors in reuse success," Journal of management of information systems, vol. 18, no. 1, 2001.

[19] J. Spased, J. Bessant, D. Partington, D. Tranfield, and M. Young, "Team working and knowledge management: A review of converging themes," International journal of management reviews, vol. 4, no. 1, 2002, pp. 79.

[20] C. Davidson and P. Voss, Knowledge management: An introduction to creating competitive advantage from Intellectual capital, Auckland: Tandem Press, 2002

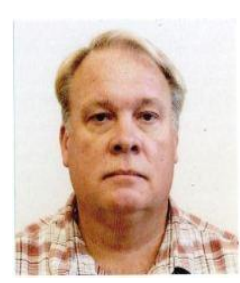

Bob Barrett became a Member of IEDRC in 2011. He has an Ed.D. in the field of Human Resource Development from The George Washington University in Washington, DC. He has been teaching at American Public University for the past ten years, and he has been actively teaching online for the past twelve years. He is an adjunct instructor with other online programs, as well as a being a course developer and online teacher trainer. His research interests include online learning, disability, teacher training, knowledge management, and intellectual capital. He has spoken extensively at various international conferences in Europe, South America, and Asia. 